\title{
ON THE ERDÖS-MORDELL INEQUALITY FOR TRIANGLES IN TAXICAB GEOMETRY
}

\section{Maja Petrović, Branko MalešEvić And Bojan BanjaC}

\begin{abstract}
In this paper the Erdös-Mordell's inequality is examined for the case of a triangle $A B C$ in the taxicab plane geometry. It is shown that the Erdös-Mordell's inequality $R_{A}+R_{B}+$ $R_{C} \geqslant w\left(r_{a}+r_{b}+r_{c}\right)$ holds for triangles with appropriate positions for its points $A, B$ and $C$, if $w=3 / 2$.
\end{abstract}

Mathematics subject classification (2010): 51M16, 51K05.

Keywords and phrases: Erdös-Mordell inequality, taxicab geometry.

\section{REFERENCES}

[1] O. Bottema, R. Ž. Djordjević, R. R. Janić, D. S. Mitrinović and P. M. Vasić, Geometric Inequalities, Wolters-Noordhoff Publishing, Groningen, The Netherlands, 1969.

[2] H. Colakoglu, On the distance formulae in the generalized taxicab geometry, Turkish J. Math. 43, 3 (2019), 1578-1594.

[3] N. Dergiades, Signed distances and the Erdös-Mordell inequality, Forum Geom. 4, (2004), 67-68.

[4] P. ERdös, Problem 3740, Amer. Math. Monthly 42, 396, 1935.

[5] M. GHANDEHARI AND H. MARTINI, On the Erdös-Mordell inequality for normed planes and spaces, Studia Sci. Math. Hungar. 55, 2 (2018), 174-189.

[6] H. S. KasAna And K. D. Kuma, Introductory Operations Research: Theory and Applications, Springer 2004.

[7] R. Kaya, Z. AkÇA, I. GünAltili, And M. ÖZCAn, General equation for taxicab conics and their classification, Mitt. Math. Ges. Hamburg 19, (2000), 135-148.

[8] I. Kocayusufoglu, Isoperimetric inequality in taxicab geometry, Math. Inequal. Appl. 9, 2 (2006), 269-272.

[9] E. F. Kraus, Taxicab Geometry: An Adventure in Non-Euclidean Geometry, Dover Publications, New York, 1986.

[10] J. LiU, Sharpened versions of the Erdös-Mordell inequality, J. Inequal. Appl. 2015, 206 (2015), 1-12.

[11] J. LIU, Refinements of the Erdös-Mordell inequality, Barrow's inequality, and Oppenheim's inequality, J. Inequal. Appl. 2016, 9 (2016), 1-18.

[12] J. LiU, Two New Weighted Erdös-Mordell Type Inequalities, Discrete Comput. Geom. 59, 3 (2018), $707-724$.

[13] J. LiU, New refinements of the Erdös-Mordell inequality, J. Math. Inequal. 12, 1 (2018), 63-75.

[14] J. LiU, New Refinements of the Erdös-Mordell Inequality and Barrow's Inequality, Mathematics 7, 8 (2019), 1-12.

[15] J. LIU, An Improved Result of a Weighted Trigonometric Inequality in Acute Triangles with Applications, J. Math. Inequal. 14, 1 (2020), 145-158.

[16] B. Malešević, M. Petrović, M. Obradović, And B. Popkonstantinović, On the Extension of the Erdös-Mordell Type Inequalities, Math. Inequal. Appl. 17, 1 (2014), 269-281.

[17] K. Menger, You will like Geometry, Guilddbook of the Illinois Institue of Technology Geometry Exhibit, Museum of Science and Industry, Chicago, IL, 1952.

[18] D. S. Mitrinović, J. PeČArić And V. Volenec, Recent Advances in Geometric Inequalities, Springer, 1989. 
[19] L. J. Mordell, Solution of Problem 3740, Amer. Math. Monthly 44, (4) (1937), 252-254.

[20] M. ÖZCAN, S. EKMEKÇI, AND A. BAYAR, A note on the variation of the taxicab lengths under rotations, The Pi Mu Epsilon Journal, 11, (2002), 381-384.

[21] V. PambuCCIAN, The Erdös-Mordell inequality is equivalent to non-positive curvature, J. Geom. 88, (2008), 134-139.

[22] N. SönmeZ, A taxicab version of the Erdös-Mordell theorem, Kragujevac J. Math. 32 (2009), 157164.

[23] P. WAlKeR, The Erdös-Mordell theorem in the exterior domain, Int. J. Geo. 5, 1 (2016), 31-38. 